\title{
Health care professionals and end-of-life care during the COVID-19 pandemic
}

\author{
Esther Angélica Luiz Ferreira ${ }^{*}$ (1), Cristina Ortiz Sobrinho Valete ${ }^{1}$ (1), \\ André Filipe Junqueira dos Santos ${ }^{2}$ (1) , Juliana Nalin de Souza Passarini ${ }^{3}(\mathbb{B}$, \\ Alexandre Ernesto Silva ${ }^{4}$ (D) Michelle Uchida Miwa ${ }^{5}$
}

\begin{abstract}
SUMMARY
OBJECTIVE: The aim of this study was to estimate self-perception of anguish and low quality of life among health care professionals who cared for the dying patients during the COVID-19 pandemic and to determine the characteristics of health care professionals and patients and end-of-life care.

METHODS: An online survey that included health care professionals who cared for the dying patient from July 1 to October 31,2020 was conducted. Low quality of life, anguish, characteristics of patients and health care professionals, and end-of-life care were recorded. Poisson regression was performed to assess the predictors of anguish and low quality of life.

RESULTS: A total of 102 health care professionals, including 14 males (13.7\%), with a median age of 37 years, composed of 41 physicians (40.2\%), 36 physiotherapists (35.3\%), and 25 nurses (24.5\%) were included in this study. Self-perception of anguish occurred in $69.6 \%$ and was associated with physicians and disagreement with end-of-life care offered. Low quality of life was reported in $64.7 \%$ and was associated with not having time to talk to patients' relatives. The agreement that medical care was enough reduced self-perception of low quality of life. CONCLUSION: Self-reported anguish was more frequent in physicians and when the disagreement about end-of-life care occurred. Low quality of life was more frequent when health care professionals did not have time to talk to patients' relatives and was less frequent when health care professionals agreed that medical care was enough. Strategies should be done by health services to reduce the impact of the pandemic on health care professionals.

KEYWORDS: COVID-19. COVID-19 pandemic. Palliative care. End-of-life care. Assisted death. Grief.
\end{abstract}

\section{INTRODUCTION}

The COVID-19 pandemic represents a severe threat to public health. Aiming at reducing the infection rate, social distancing and isolation measures have been adopted. Nevertheless, they led to social and behavioral changes that considerably altered the human relationship with the environment ${ }^{1}$.
For patients and their relatives, the coronavirus crisis has caused fear and anxiety exacerbated by the lack of information about this new disease. If the health system capacity is exhausted, these hardships may increase due to the unavailability of medical services and equipment to provide them support ${ }^{2}$.

\footnotetext{
'Universidade Federal de São Carlos, Medicine Department - São Carlos (SP), Brazil.

${ }^{2}$ Oncological Institute of Ribeirão Preto, Oncoclínicas Group, Palliative Care Service - Riberão Preto (SP), Brazil

${ }^{3}$ Universidade Estadual de Campinas, Faculty of Medical Sciences, Department of Clinical Medicine - Campinas (SP), Brazil.

${ }^{4}$ Universidade Federal de São João del-Rei, Medical and Nursing Course - São João del Rei (MG), Brazil.

${ }^{5}$ Hospital de Amor de Barretos, Department of Palliative Care - Barretos (SP), Brazil.

*Corresponding author: estherferreira@ufscar.br

Conflicts of interest: the authors declare there are no conflicts of interest. Funding: none.

Received on July 15, 2021. Accepted on July 20, 2021.
} 
In these circumstances, essential principles that orient the medical support of the ill patients, such as the attention to the needs and preferences of the ill person and their families, may be compromised. Emotional, cognitive, physical, and behavioral responses following the demise are common elements of uncomplicated grief ${ }^{3}$. The usual grief experiences during the COVID-19 pandemic were often interrupted, and thus it is imperative to reconsider the standard approaches and find new solutions. For many hospitalized patients, for example, visits were limited or even prohibited, regardless of having received a diagnosis of COVID-19 or not. For the grieving relatives, funerals and burials were postponed or ensued at a distance, often without the presence and warmth of their loved ones ${ }^{4}$.

Overwhelmed hospitals demanded the transfer of patients to other health care units. These experiences can be traumatic, just as passing away in a ward or other facilities dedicated to the treatment of patients with COVID-19, which may also lead to a psychological stigma. It is known that family members of those who died at a hospital or an intensive therapy unit represent a larger risk for extended grief and depression ${ }^{5}$. The impossibility of a "farewell" between the family and the deceased is associated with complicated grief. Studies demonstrate that severe symptoms of anticipatory grief, lower levels of social support, lack of preparation and planning for death, and guilt are risk factors for complicated grief and depression after bereavement. These factors are relevant to the COVID19 pandemic context ${ }^{6-9}$.

In Brazil, the pandemic stressed the health system, which already operated at its limit in normal situations, leading to the collapse of medical group ${ }^{10}$. Health care professionals handled an overwhelming flow of severely ill patients, the ailment of their medical colleagues, and the moral suffering due to their inability to provide basic care that they considered humane and necessary. Along with their workload, they also had to manage a preoccupation with their own health and that of their families ${ }^{11}$.

In light of these data, this study aimed to estimate self-perception of anguish and low quality of life among health care professionals who cared for the dying patients during the COVID-19 pandemic. Also, it intended to determine the characteristics of health care professionals and patients and end-of-life care associated with self-perception of anguish and low quality of life.

\section{METHODS}

In this online survey, we enrolled 102 health care professionals who cared for the dying patients in their last days of life, from July 1 to October 31, 2020. This article writing followed the STROBE form for the cross-sectional studies ${ }^{12}$.
The survey form was a short version from the international form "Care of the Dying Evaluation" (iCODE) that focused on the last 2 days of life and the grief period, asked about the quality of patient care and family support ${ }^{13}$, and included questions about COVID-19. The translation, adaptation, and use of form were approved. The protocol proposed by Kulis et al. was used ${ }^{14}$.

Inclusion criteria: health care professionals who took care of a patient in their last 2 days of life.

Exclusion criteria: incomplete forms.

Quality of life was registered on a scale from 1-7 and defined by the World Health Organization as "the individual perception about his life position, according to cultural context and values systems in which he lives and in relation to his objectives, expectations, patterns, and concerns"15.

Health care professional characteristics (i.e., age, sex, and professional category) and patient characteristics (e.g., age, sex, SARS-CoV-2 infection, and if he/she felt pain always or sometimes) were registered. End-of-life care offered for the last 2 days (agreement with end-of-life care offered, a shared decision regarding limited life care support, have time to talk to patients' relatives, the agreement that medical care was enough, if visits were allowed, if emotional and spiritual support was offered to patients' relatives, the place where care was offered, and if death occurred in a COVID-19 division) was investigated.

Outcome variables were self-perception of low quality of life ( $\leq 4)$ and anguish (yes/no) of health care professionals. The following three hierarchical blocks of variables were analyzed: health care professional characteristics (distal variables), patient characteristics (intermediate variables), and end-of-life care (proximal variables).

Statistical analysis: All statistical analyses were done using Stata software, version 13 (https://www.stata.com/). To test if the variables were normally distributed, the KolmogorovSmirnov test was performed. For continuous variables, data were presented as the median and interquartile range (IQR). Categorical variables were presented as number values, percentage, and $95 \%$ confidence interval $(95 \% \mathrm{CI})$. To determine the predictors of low quality of life and anguish, a Poisson regression (robust estimation and log link function) was used to estimate crude prevalence ratios. The variables with a significance of $\mathrm{p}<0.20$ were included in blocks in the hierarchical multivariate analysis. The multivariate hierarchical model estimated adjusted prevalence ratios. A $\mathrm{p}<0.05$ was considered statistically significant.

This study was approved by the São Carlos Federal University Research Ethics Committee (CAAE 31896820.1.0000.5504). Informed consent was obtained from all participants. 


\section{RESULTS}

The number of health care professionals included was 102; 14 of them $(13.7 \%)$ were males, with a median age of 37 years (IQR 33-42). Among health care professionals, 41 (40.2\%) were physicians, 25 (24.5\%) were nurses, and $36(35.3 \%)$ were physiotherapists.

Patients' median age was 60 years (IQR 40-73), and 65 $(63.7 \%)$ of them were males. Patients were taken care in 14 states, allocated in the 5 Brazilian regions. São Paulo state represented 63.8\%, followed by Minas Gerais (6.9\%), Bahia (5.9\%), and Rio de Janeiro (5.9\%). Ninety-four (92.1\%) patients were taken care of in a hospital, where 52 of them (55.3\%) died at a COVID-19 intensive care unit, 20 (21.2\%) of them died at a COVID-19 infirmary, $16(17.0 \%)$ of them died at a general infirmary, and $7(7.4 \%)$ of them died at a general intensive care unit.

There was a shared decision regarding the limited life support in $59(57.9 \%)$ patients. The most frequent decision was do-not-resuscitate in 43 of them (72.9\%) followed by do-not-admit at the intensive care unit in 11 cases (18.6\%). The most frequent reason to limit the life support was the clinical condition in 46 patients (77.9\%). Figure 1 shows the other end-of-life care.

Self-perception of anguish was referred by 71 (69.6\%) health care professionals. The predictors of anguish were identified using univariate and multivariate Poisson regression analysis as shown in Table 1. Physicians were associated with $37 \%$ more anguish $(\mathrm{p}=0.02)$ and disagree with end-of-life care was associated with $42 \%$ more anguish $(\mathrm{p}=0.006)$.
Low quality of life ( $\leq 4)$ was reported by 66 (64.7\%) health care professionals. The predictors of low quality of life were identified using univariate and multivariate Poisson regression analysis as shown in Table 2 . Low quality of life was more frequently reported in $46 \%$ where health care professionals did not have time to talk to patients' relatives $(\mathrm{p}=0.02)$ and $30 \%$ less frequent where health care professionals agreed that medical care was enough $(\mathrm{p}=0.01)$.

\section{DISCUSSION}

This study analyzed the psychosocial impact of the COVID19 pandemic in health care professionals, exploring communication, symptom control, support, and comfort offered to relatives of end-of-life patients.

Self-perception of anguish was referred by $69.6 \%$ of health care professionals and was associated with physicians and disagreement with end-of-life care. As anguish is a condition related to negative feelings and suffering ${ }^{16}$, we hypothesized that physicians had more anguish probably because of some factors such as the impotence feeling, as many patients died in a short time, regardless of all procedures and the responsibility of certifying death. In a multidisciplinary team, physicians usually assume a team-leader position and must take hard decisions that are extremely stressful. The high prevalence of anguish reflects moral suffering, is concerning, and may reflect harm to the work environment ${ }^{16,17}$. Reinforcing compassion could

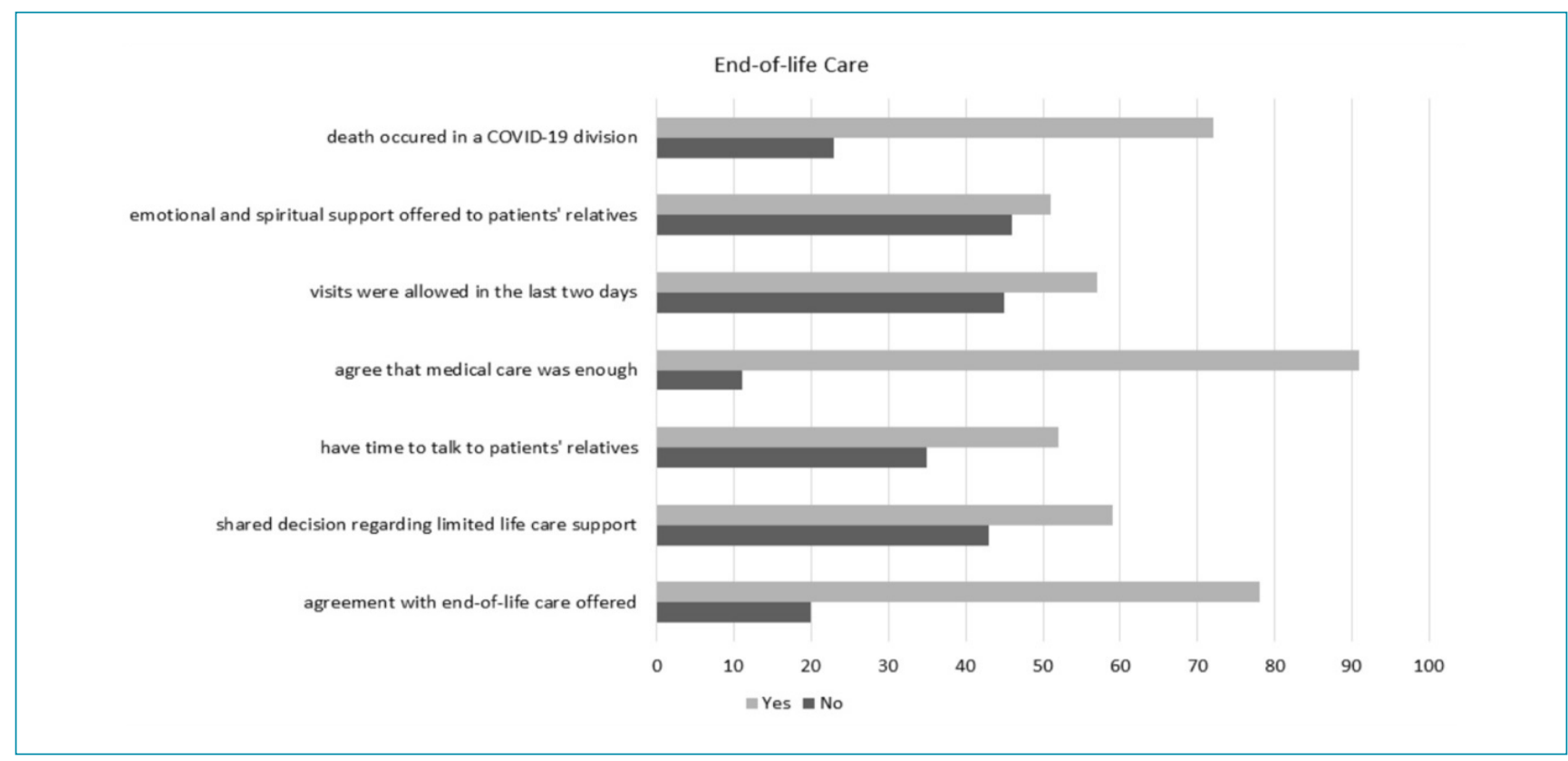

Figure 1. Health professionals and patients' characteristics and end of life care. 
Table 1. Univariate and multivariate hierarchical Poisson regression for the predictors of self-perception of anguish in health care professionals.

\begin{tabular}{|c|c|c|c|c|c|c|}
\hline & Anguish (\%) & CPR & p-value* & APR & $95 \% \mathrm{Cl}$ & p-value* \\
\hline \multicolumn{7}{|c|}{ Health care professionals } \\
\hline \multicolumn{7}{|l|}{ Age (years) } \\
\hline$>37$ & 70.0 & 1.01 & \multirow{2}{*}{0,93} & \multirow{2}{*}{\multicolumn{3}{|c|}{ Not included }} \\
\hline$\leq 37$ & 69.2 & 1 & & & & \\
\hline \multicolumn{7}{|l|}{ Sex } \\
\hline Male & 50.0 & 0.68 & \multirow{2}{*}{0.17} & \multirow{2}{*}{\multicolumn{3}{|c|}{ Not included }} \\
\hline Female & 72.7 & 1 & & & & \\
\hline \multicolumn{7}{|l|}{ Professional category } \\
\hline Physician & 78.0 & 1.24 & \multirow{2}{*}{0.09} & \multirow{2}{*}{1.37} & \multirow{2}{*}{$1.05-1.79$} & \multirow{2}{*}{0.02} \\
\hline Others & 63.9 & 1 & & & & \\
\hline & & & nts & & & \\
\hline \multicolumn{7}{|l|}{ Age (years) } \\
\hline$>60$ & 72.0 & 1.06 & \multirow{2}{*}{0.60} & \multirow{2}{*}{\multicolumn{2}{|c|}{ Not included }} & \\
\hline$\leq 60$ & 67.3 & 1 & & & & \\
\hline \multicolumn{7}{|l|}{ Sex } \\
\hline Male & 70.0 & 1.01 & \multirow{2}{*}{0.89} & \multirow{2}{*}{\multicolumn{3}{|c|}{ Not included }} \\
\hline Female & 69.4 & 1 & & & & \\
\hline \multicolumn{7}{|l|}{ SARS-CoV-2 infection } \\
\hline Confirmed or probable & 67.5 & 0.95 & \multirow{2}{*}{0.76} & \multirow{2}{*}{\multicolumn{3}{|c|}{ Not included }} \\
\hline No & 70.8 & 1 & & & & \\
\hline Felt pain all the time or sc & times & & & & & \\
\hline Yes & 64.4 & 0.87 & & & & \\
\hline No & 73.6 & 1 & 0.32 & & Not included & \\
\hline & & & fe care & & & \\
\hline Agreement with end-of-li & care offered & & & & & \\
\hline No & 85.0 & 1.32 & בחת ח & 112 & 110182 & ค ค०६ \\
\hline Others & 64.1 & 1 & 0.02 & 1.42 & $1.10-1.83$ & 0.006 \\
\hline Shared decision regarding & nited life care $s$ & & & & & \\
\hline Yes & 71.0 & 1.05 & & & & \\
\hline Others & 67.0 & 1 & 0.68 & & Not Included & \\
\hline Have time to talk to patie & relatives & & & & & \\
\hline No & 80.0 & 1.09 & & & & \\
\hline Others & 73.0 & 1 & 0.45 & & Not included & \\
\hline Agree that medical care $v$ & enough & & & & & \\
\hline Yes & 67.0 & 0.73 & & & & \\
\hline Others & 90.0 & 1 & 0.01 & & Not included & \\
\hline Visits were allowed in the & t 2 days & & & & & \\
\hline Yes & 63.1 & 1 & 10 & & Not included & \\
\hline No & 77.7 & 1.23 & 0.10 & & Nol incluared & \\
\hline Emotional and spiritual st & ort offered to $p$ & nts' rel & & & & \\
\hline No/probably no & 73.0 & 1 & 056 & & Net included & \\
\hline Yes & 68.0 & 0.92 & 0.56 & & Not Included & \\
\hline Place where care was offe & & & & & & \\
\hline Hospital & 69.1 & 0.92 & & & & \\
\hline Others & 75.0 & 1 & 0.10 & & Not Included & \\
\hline Death occurred in a COV & 19 division & & & & & \\
\hline Yes & 69.4 & 0.93 & & & & \\
\hline No & 73.9 & 1 & 0.55 & & Not included & \\
\hline
\end{tabular}

95\%Cl: 95\% confidence interval; CPR: crude prevalence rate for univariate analysis; APR: adjusted prevalence rate for multivariate analysis. * $\mathrm{p}$-value associated with Poisson regression. 
Table 2. Univariate and multivariate hierarchical Poisson regression for the predictors of self-perception of quality of life in health care professionals.

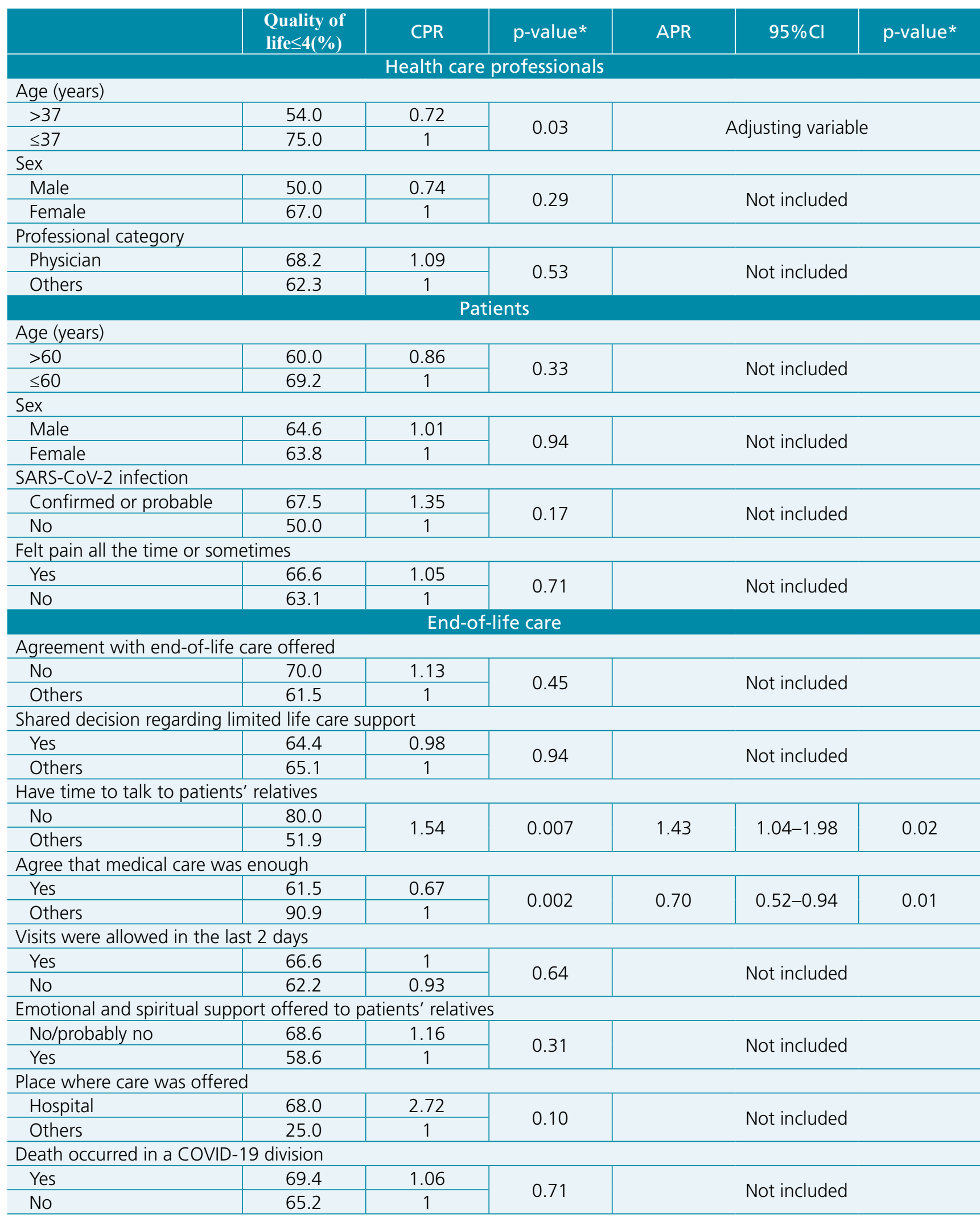

95\%Cl: 95\% confidence interval; CPR: crude prevalence rate for univariate analysis; APR: adjusted prevalence rate for multivariate analysis. *p-value associated with Poisson regression. 
help health care professionals overcome anguish ${ }^{18}$. The disagreement with end-of-life care may reflect communication difficulties during the COVID-19 pandemic.

Low quality of life was referred by $64.7 \%$ of health care professionals and was associated with not having time to talk to patients' relatives. Effective verbal and non-verbal communication are the cornerstones of health care, provide possibilities in decision-making to the patients' relatives, and may reduce stress and disagreements with the health care team and between relatives $^{19}$. In contrast, literature has shown that bereaved relatives who did not receive effective communication during the death and dying process of their relative demonstrate a bad understanding of the clinical aspects of the disease, resulting in wrong decisions, hassles, fear, guilt, and frustration ${ }^{19}$. Low quality of life was less frequent when health care professionals agreed that medical care was enough. This also reflects the importance of an adequate work environment, with the necessary resources, where physical and mental aspects are articulated ${ }^{16}$.

In this study, shared decisions regarding limiting life support were frequent, and this was surprising as we considered that the availability of palliative care teams was estimated to be present in less than $5 \%$ of all hospitals with less than 50 beds in Brazil ${ }^{20}$. The most frequent decision was do-not-resuscitate. Forte et al. also reported that do-not-resuscitate was the limiting support most frequently reported by physicians who attended at an intensive care unit ${ }^{21}$. The decision to withdraw life support in end-of-life patients requires medical education and the recognition of unnecessary procedures ${ }^{22}$. This issue has been addressed in graduation courses.

Half of the health care professionals referred that visits were allowed and emotional and spiritual support to patients' relatives were offered. These attitudes contribute to prevent relatives' depression and enhance satisfaction with end-of-life care ${ }^{23}$.
This study has some limitations. First, it was a cross-sectional study and temporal relations were not assessed. The online survey design may include selection bias. Other studies are needed to confirm our results.

\section{CONCLUSIONS}

Based on our study findings, health care professionals' self-perception of anguish and low quality of life was high. Anguish was more frequent in physicians and when the disagreement about end-of-life care occurred. Low quality of life was more frequent when health care professionals did not have time to talk to patients' relatives and was less frequent when health care professionals agreed that medical care was enough. Strategies should be developed by health services to reduce the impact of the pandemic on health care professionals.

\section{ACKNOWLEDGMENT}

We thank Dr. Vilma Adriana Tripodoro, Instituto de Investigaciones Médicas Alfredo Lanari (Universidad de Buenos Aires) and Ida Korfage and Agnes van der Heide, Erasmus MC, University Medical Center Rotterdam.

\section{AUTHORS" CONTRIBUTIONS}

Ealf: Conceptualization, Data curation, Formal Analysis, Writing - review \& editing. COSV: Data curation, Formal Analysis, Writing - review \& editing. AFJS: Conceptualization, Writing - original draft. JNSP: Conceptualization, Writing - review \& editing. AES: Conceptualization, Writing review \& editing. MUM: Conceptualization, Writing review \& editing.

\section{REFERENCES}

1. Ogden RS. The passage of time during the UK Covid-19 lockdown. PLoS One. 2020;15(7):e0235871. https://doi. org/10.1371/journal.pone.0235871

2. Yang J, Zheng Y, Gou X, Pu K, Chen Z, Guo Q, et al. Prevalence of comorbidities and its effects in patients infected with SARS-CoV-2: a systematic review and meta-analysis. Int J Infect Dis. 2020;94:91-5. https://doi.org/10.1016/j. ijid.2020.03.017

3. Worden JW. Grief counseling and grief therapy: a handbook for the mental health practitioner. 5th ed. Nova York: Springer Publishing; 2018. 352 p

4. Wallace $C L$, Wladkowski SP, Gibson A, White P. Grief during the COVID-19 pandemic: considerations for palliative care providers. J Pain Symptom Manage. 2020;60(1):e70-6. https:// doi.org/10.1016/j.jpainsymman.2020.04.012
5. Wright AA, Keating NL, Balboni TA, Matulonis UA, Block SD, Prigerson HG. Place of death: correlations with quality of life of patients with cancer and predictors of bereaved caregivers' mental health. J Clin Oncol. 2010;28(29):4457-64. https:// doi.org/10.1200/JCO.2009.26.3863

6. Otani H, Yoshida S, Morita T, Aoyama M, Kizawa Y, Shima $Y$, et al. Meaningful communication before death, but not present at the time of death itself, is associated with better outcomes on measures of depression and complicated grief among bereaved family members of cancer patients. J Pain Symptom Manage. 2017;54(3):273-9. https://doi.org/10.1016/j. jpainsymman.2017.07.010

7. Romero MM, Ott CH, Kelber ST. Predictors of grief in bereaved family caregivers of person's with Alzheimer's disease: a prospective study. Death Stud. 2014;38(6-10):395-403. https:// doi.org/10.1080/07481187.2013.809031 
8. Lobb EA, Kristjanson L, Aoun SM, Monterosso L, Halkett GK, Davies A. Predictors of complicated grief: a systematic review of empirical studies. Death Stud. 2010;34(8):673-98. https:// doi.org/10.1080/07481187.2010.496686

9. Li J, Tendeiro JN, Stroebe M. Guilt in bereavement: its relationship with complicated grief and depression. Int J Psychol. 2019;54(4):454-61. https://doi.org/10.1002/ijop.12483

10. Panagioti M, Geraghty K, Johnson J, Zhou A, Panagopoulou E, Chew-Graham C, et al. Association between physician burnout and patient safety, professionalism, and patient satisfaction: a systematic review and meta-analysis. JAMA Intern Med. 2018;178(10):1317-31. https://doi.org/10.1001/ jamainternmed.2018.3713

11. Restauri N, Sheridan AD. Burnout and posttraumatic stress disorder in the coronavirus disease 2019 (COVID-19) pandemic: intersection, impact, and interventions. J Am Coll Radiol. 2020;17(7):921-6. https://doi.org/10.1016/j.jacr.2020.05.021

12. Malta M, Cardoso LO, Bastos Fl, Magnanini MM, Silva CM. STROBE initiative: guidelines on reporting observational studies. Rev Saude Publica. 2010;44(3):559-65. https://doi. org/10.1590/s0034-89102010000300021

13. Mayland CR, Gerlach C, Sigurdardottir K, Hansen MIT, Leppert W, Stachowiak A, et al. Assessing quality of care for the dying from the bereaved relatives' perspective: Using pre-testing survey methods across seven countries to develop an international outcome measure. Palliat Med. 2019;33(3):357-68. https:// doi.org/10.1177/0269216318818299

14. Koller M, Aaronson NK, Blazeby J, Bottomley A, Dewolf $L$, Fayers $\mathrm{P}$, et al. Translation procedures for standardised quality of life questionnaires: The European Organisation for Research and Treatment of Cancer (EORTC) approach. Eur J Cancer. 2007;43(12):1810-20. https://doi.org/10.1016/j. ejca.2007.05.029
15. The World Health Organization Quality of Life assessment (WHOQOL): position paper from the World Health Organization. Soc Sci Med. 1995;41(10):1403-9. https:// doi.org/10.1016/0277-9536(95)00112-k

16. Caram CS, Ramos FRS, Almeida NG, Brito MJM. Sofrimento moral em profissionais de saúde: retrato do ambiente de trabalho em tempos de COVID-19. Rev Bras Enferm. 2021;74(Suppl 1):e20200653. https://doi.org/10.1590/0034-7167-2020-0653

17. Shanafelt T, Ripp J, Trockel M. Understanding and addressing sources of anxiety among health care professionals during the COVID-19 pandemic. JAMA. 2020;323(21):2133-4. https:// doi.org/10.1001/jama.2020.5893

18. Singer T, Klimecki OM. Empathy and compassion. Curr Biol. 2014;24(18):R875-8. https://doi.org/10.1016/j.cub.2014.06.054

19. Queiroz AC, Silva MP, Dantas MCS, Fonseca AC, Brito DTF, Agra G. Cuidados voltados aos familiares de pessoas em finitude humana. Research, Society and Development. 2021;10(2):e7310212151. https://doi.org/10.33448/rsd-v10i2.12151

20. Santos AFJ, Ferreira EAL, Guirro UBP. Atlas dos cuidados paliativos no Brasil 2019. São Paulo: ANCP; 2020.

21. Forte DN, Vincent JL, Velasco IT, Park M. Association between education in EOL care and variability in EOL practice: a survey of ICU physicians. Intensive Care Med. 2012;38(3):404-12. https://doi.org/10.1007/s00134-011-2400-4

22. Moritz RD, Machado FO, Heerdt M, Rosso B, Beduschi G. Evaluation of medical decisions at the end-of-life process. Rev Bras Ter Intensiva. 2009;21(2):141-7. PMID: 25303343

23. Curtis JR, Treece PD, Nielsen EL, Gold J, Ciechanowski PS, Shannon SE, Khandelwal N, Young JP, Engelberg RA. Randomized trial of communication facilitators to reduce family distress and intensity of end-of-life care. Am J Respir Crit Care Med. 2016;193(2):154-62. https://doi.org/10.1164/ rccm.201505-09000C 